\title{
Quantificaçáo neuronal no córtex cerebral de camundongos sob o uso do chá de Ayahuasca
}

\author{
Neuronal quantification in mice cerebral cortex under use of Ayahuasca tea
}

\author{
Janille Santos Corrêa ${ }^{1}$, Vanessa Almeida Amorin ${ }^{1}$, Denismar Alves Nogueira ${ }^{2}$, \\ Evelise Aline Soares', Flávia da Ré Guerra', Geraldo José Medeiros Fernandes', \\ Wagner Costa Rossi Júnior ${ }^{6}$, Alessandra Esteves ${ }^{7}$
}

\section{RESUMO}

Objetivo. A Ayahuasca, administrada em forma de chá, é resultado da cocção entre Banisteriopsis caapi e Psychotria viridis para fins religiosos, tendo ação psicoativa. $\mathrm{O}$ objetivo deste estudo foi analisar quantitativamente corpos celulares no córtex cerebral de camundongos sob o uso do extrato de Ayahuasca. Método. Foram utilizados 15 camundongos, divididos em três grupos: grupo controle (G1), tratado com solução fisiológica por 15 dias; G2 tratado com uma única dose do extrato de ayahuasca e G3 tratado com o extrato de ayahuasca durante 15 dias consecutivos, na dose padrão para os dois grupos experimentais de $30 \mathrm{mg} / \mathrm{ml}$. Foi confirmada a presença de alcaloides no chá de Ayahuasca e a análise da quantidade de corpos celulares de neurônios foi realizada com o auxílio de um Sistema de Analisador de Imagens. Resultados. Não haver diferenças entre a quantidade dos corpos celulares no córtex cerebral do G1 em relaçáo aos grupos G2 e G3. Conclusáo. A utilização do chá de Ayahuasca na dose e tempo utilizados neste experimento, não causaram nenhum tipo de alteração quantitativa de corpos celulares de neurônios no córtex cerebral dos camundongos.

Unitermos. Ayahuasca, Neurônios, Córtex Cerebral, Camundongos

Citaçáo. Corrêa JS, Amorin VA, Nogueira DA, Soares EA, Guerra FR, Fernandes GJM, Rossi-Junior WC, Estaves A. Quantificação neuronal no córtex cerebral de camundongos sob o uso do chá de Ayahuasca.

\begin{abstract}
Objective. Ayahuasca, administered as infusion (tea), is the result of Banisteriopsis caapi and Psychotria viridis boiling for religious rites, and has psychoactive action. This study aimed to quantify the number of neuron cell bodies of cerebral cortex in mice under the use of Ayahuasca extract. Method. 15 mice were divided into 3 groups: G1 (control), treated with saline solution for 15 days; G2, treated with a single dose of $30 \mathrm{mg} / \mathrm{ml}$ of Ayahuasca extract; and G3, treated with Ayahuasca extract during 15 days using the same dose each day. The presence of the alkaloids in the infusion was confirmed, and to quantify the number of neuron cell bodies we used the sample random counting method. Results. There was no difference in the neuron cell bodies number for limbic, sensory, and motor areas comparing G1 to G2 and G3. Conclusion. We concluded that the use of Ayahuasca tea in the dose and time designed for this experiment do not cause changes in neuron cell bodies number in the analyzed cerebral cortex.
\end{abstract}

Keywords. Ayahuasca, Neuron, Cerebral Cortex, Mice

Citation. Corrêa JS, Amorin VA, Nogueira DA, Soares EA, Guerra FR, Fernandes GJM, Rossi-Junior WC, Estaves A. Neuronal quantification in mice cerebral cortex under use of Ayahuasca tea.

Trabalho realizado no Departamento de Anatomia da Universidade Federal de Alfenas, Alfenas-MG, Brasil.

1.Graduanda em Biomedicina pela UNIFAL, Alfenas-MG, Brasil

2.Agrônomo, Doutor em Estatística e Experimentação Agropecuária pela Universidade Federal de Lavras, Lavras-MG, Brasil

3.Fonoaudióloga, Doutora, Docente da disciplina de Anatomia da UNIFAL, Alfenas-MG, Brasil

4.Bióloga, Doutora, Docente da disciplina de Anatomia da UNIFAL, Alfenas-MG, Brasil

5.Médico, Doutor, Docente da disciplina de Anatomia da UNIFAL, Alfenas-MG, Brasil

6.Cirurgiáo dentista, Doutor, Docente da disciplina de Anatomia da UNIFAL, Alfenas-MG, Brasil.

7.Médica Veterinária, Doutora, Docente da disciplina de Anatomia da UNIFAL, Alfenas-MG, Brasil.
Endereço para correspondência: Profa. Dra. Alessandra Esteves Universidade Federal de Alfenas, Departamento de Anatomia Rua Gabriel Monteiro da Silva, 700 CEP 37130-000, Alfenas-MG, Brasil Fone: 3532991302

E-mail: aesteves@unifal-mg.edu.br Aceito em: 04/11/14

Conflito de interesses: não 
A Ayahuasca se constitui na forma de chá e é preparada a partir de duas plantas: Banisteriopsis caapi e Psychotria viridis. É comumente utilizada em rituais religiosos e, acredita-se que o chá permita uma cura espiritual, psicológica, emocional e física; por isso ele é referido como "enteogênico", o que significa "contém Deus dentro" 1 .

Em termos de atividade farmacológica, a Ayahuasca é única, já que esta depende da interação sinérgica entre a atividade dos alcalóides das plantas combinadas. Um dos componentes, a casca do cipó de Banisteriopsis caapi, contem alcalóides $\beta$-carbolinas, como harmina, tetrahidroharmina e harmalina ${ }^{2}$, os quais são potentes inibidores da monoaminoxidase; o outro componente, as folhas de Psychotria viridis ou espécies relacionadas, contem um potente agente psicoativo, o N,N-dimetiltriptamina (DMT). O DMT não é ativado oralmente quando ingerido isoladamente, mas pode ser ativado oralmente na presença de um inibidor da MAO (iMAO) periférico - e esta interação é a base da ação psicotrópica da Ayahuas$\mathrm{ca}^{3}$. Além disso, o DMT é um alcalóide indol muito semelhante à serotonina (5HT) tanto na estrutura molecular como na atividade 4 .

A 5-hidroxitriptamina (5-HT, serotonina) é encontrada nos núcleos da rafe e no tronco cerebral que contém neurônios serotoninérgicos que sintetizam, armazenam e libera serotonina como seu transmissor. Os neurônios serotoninérgicos cerebrais estâo envolvidos em uma ampla gama de funções tais como sono, humor, sentido da dor, controle da temperatura e regulação da pressão arterial. Além dessas funções fisiológicas normais, pode estar relacionada também com condiçóes patológicas, tais como enxaqueca, ansiedade e depressão 5 .

No contexto apresentado inicialmente em relaçáo da estrutura cerebral, e apoiado em relatos de que o chá da ayahuasca causa efeitos neurológicos adversos; o presente estudo visa observar possíveis alteraçóes quantitativas de corpos celulares de neurônios no córtex cerebral de camundongos sob o uso do extrato de Ayahuasca comparando o grupo controle aos grupos experimentais.

\section{MÉTODO}

\section{Amostra}

Foram utilizados para este experimento, $15 \mathrm{ca}-$ mundongos Swiss machos com peso aproximado de 35 gramas, idade de 3 meses (jovens-adultos). Os animais tiveram livre acesso à água e comida, sendo mantidos em jejum somente durante o período da noite precedente à administração do extrato feita logo pela manhâ, a fim de se aumentar a velocidade absorção.

Os camundongos foram distribuídos em 3 grupos distintos: G1: Controle, 5 camundongos tratados com solução fisiológica durante 15 dias; G2: 5 camundongos tratados com aplicação intraperitoneal única, de extrato de ayahuasca; G3: 5 camundongos tratados com aplicação intraperitoneal de extrato de ayahuasca, durante 15 dias consecutivos.

Este trabalho teve parecer favorável e foi registrado no comitê de ética em experimentação animal sob o n²66/2010.

\section{Procedimentos}

A triagem fitoquímica do chá de Ayahuasca foi realizada antes mesmo do início dos experimentos com o intuito de, obter o conteúdo do chá e se o mesmo estava dentro dos padrôes fitoquímicos para a realização deste estudo. A triagem realizada em cromatografia em camada delgada $(\mathrm{CDD})^{6,7}$ demonstrou a presença de grande quantidade de alcalóides. Além da presença, em pequena quantidade, de saponinas, flavonóides e fenóis. Todos os metabólitos pesquisados e seus respectivos resultados encontram-se na Tabela 1.

A dose de aplicaçáo, para os dois grupos experimentais (G2 e G3), foi de $30 \mathrm{mg} / \mathrm{ml}$ por via intraperitoneal, após os tratamentos especificados, os animais foram eutanasiados com halotano. Portanto, a eutanásia dos animais foi realizada: G1 após 15 dias, G2 após 12 horas decorrentes da administração e G3 após 15 dias de tratamento. Os cérebros destes animais foram coletados imediatamente após a eutanásia e fixados em solução de paraformaldeído $\mathrm{pH} 7.4$ por 12 horas após este período as amostras foram processadas seguindo-se a sequência 
Tabela 1. Triagem fitoquimica realizada em $C D D$ do extrato de Ayahuasca.

\begin{tabular}{cc}
\hline Substâncias & Quantidades \\
\hline Antraquinonas & - \\
Alcalóides & +++ \\
Saponinas & + \\
Terpenóides & - \\
Flavonóides & + \\
Fenóis & + \\
Taninos & - \\
Cumarinos & -
\end{tabular}

$(-)$ = ausência, $(+)=$ pequena quantidade $\mathrm{e}(+++)=$ grande quantidade de substâncias analisadas.

histológica convencional: desidratação em etanol, diafanização em xilol e inclusão em parafina. Foram obtidos cortes sagitais medianos e seriados com espessura de $7 \mu \mathrm{m}$ que foram corados pela técnica do Violeta Cresil.

Para a análise da quantidade de corpos celulares de neurônios usamos a metodologia de contagem aleatória simples ${ }^{8-11}$ onde analisamos, por contagem de pontos, dois campos microscópicos idênticos em cortes consecutivos de 3 cortes diferentes, totalizando seis (6) áreas analisadas por animal, feita por um Sistema de Analisador de Imagens Axiovision 4 Module Interactive Mensuerement da marca Carl Zeiss .

\section{Análise Estatística}

O presente experimento foi conduzido em Delineamento Inteiramente Casualizado (DIC) e a principal variável resposta, número médio de corpos celulares de neurônios no córtex cerebral, foram analisadas via ANOVA seguida de teste de comparaçóes múltiplas por se tratar da média de diversas observaçóes discretas (Teste Tukey). Considerou-se $\mathrm{p}<0,05$.

\section{RESULTADOS}

Os grupos não diferiram na contagem dos corpos celulares nas 3 áreas analisadas: G2 $(18,31 \pm 7,09)$, G3 $(19,47 \pm 7,38)$ e $\mathrm{G} 1(15,97 \pm 6,28 ; \mathrm{p}>0,05)$.

Os grupos não diferiram na contagem dos corpos celulares nas 3 áreas analisadas: G2 $(18,31 \pm 7,09)$, G3 $(19,47 \pm 7,38)$ e $G 1(15,97 \pm 6,28 ; p>0,05)$

\section{DISCUSSÃO}

Nenhum estudo, após levantamento bibliográfico minucioso, foi encontrado da relação do uso do chá de Ayahuasca e as alteraçóes quantitativas de corpos celulares no córtex cerebral. A maioria dos estudos sobre a utilização da Ayahuasca se concentra em seus aspectos farmacológicos e antropológicos. Portanto a discussão dos nossos resultados não nos permitiu fazer comparações de artigos já publicados, pois não encontramos trabalhos relevantes sobre o assunto.

A ação da bebida se deve à interação das $\beta$-carbolinas com o DMT presentes nas plantas, que juntas potencializam as propriedades alucinógenas de ambas isoladas, levando-se em consideração que as $\beta$-carbolinas aumentem as concentrações de $\mathrm{DMT}^{12}$ podendo provocar distúrbios comportamentais, mas não morfológicas ou quantitativas das células nervosas assim como observado neste estudo. A ação do DMT é agonista dos receptores seratoninérgicos 5-HT, o que causa efeitos como visão de imagens com os olhos fechados, delírios parecidos com sonhos e sensação de vigilância e estimulação ${ }^{13}$. As análises comportamentais e bioquímicas não foram enfoque deste presente estudo, mas que deve ser avaliado permitindo assim obtenção de novos dados.

Há evidências de que o uso de lidocaína produz dano neuronal na regiáo CA3 do hipocampo e na amígdala basolateral neste estudo foram utilizados 3 grupos: grupo I recebeu $0,9 \%$ de solução salina IP $(\mathrm{n}=9)$, o grupo II recebeu uma dose única de lidocaína $60 \mathrm{mg} /$ $\mathrm{kg}(\mathrm{n}=18)$, e grupo III recebeu $90 \mathrm{mg} / \mathrm{kg}$ intraperitoneal $(\mathrm{n}=12)$. No dia 2, 7 e 10 após o tratamento, 3 a 6 ratos por grupo foram sacrificados, os cérebros retirados e analisados observando-se que a lidocaína provoca uma alteração morfoquantitativa das regiôes estudadas ${ }^{14}$. Apesar da lidocaína ser considerada uma substâncias psicoativas assim como o chá de Ayahuasca os resultados obtidos neste presente experimento, foram um tanto diferentes, alguns fatores podem estar envolvidos como: via de administraçâo da substância, dose utilizada, forma de administração 
podem ter influenciado nos resultados negativos obtidos com o chá de Ayahuasca.

Em outro experimento que analisou cortes seriados de cérebro de Murídeos induzidos a beber ayahuasca ao invés da dieta hídrica convencional (água), não mostrou a existência e/ou presença de lesóes ou mesmo alguma anormalidade ou reposta celular visual em relação aos controles o que foi assim como observado neste presente trabalho ${ }^{15}$. O que nos leva a inferir que apesar deste estudo não mostrar alteraçôes quantitativa no córtex cerebral, não é possível afirmar que o uso do chá é seguro, pois não há conhecimento dos efeitos comportamentais, bioquímicos e morfológicos que podem se manifestar a longo prazo.

\section{CONCLUSÃO}

Conclui-se que não houve alteraçóes quantitativas de corpos celulares de neurônios no córtex cerebral de camundongos dos grupos experimentais em relação ao grupo controle, porém, não significa que o uso do chá é seguro, pois se trata de uma substância psicotrópica que pode alterar outras áreas do sistema nervoso central e é metabolizada e excretada lentamente pelo organismo, levando facilmente a efeitos tóxicos graves em altas doses. Com isso, muitos estudos sobre testes comportamentais, fisiológicos e toxicológicos mais específicos e abrangentes devem ser realizados em torno deste tema.

\section{REFERÊNCIAS}

1.Ayahuasca: A Universidade Gaia (http://www.heartoftheinitiate.com). Co- lombia: Heart of the initiate (última atualização 11/2003; citado em 09/2011). Disponível em: http://www.heartoftheinitiate.com/library/articles/ayahuasca-university-of-gaia

2.Callaway JC, Raymon LP, Hearn WL, Mckenna DJ, Grob CS, Brito GS, et al. Quantitation of N,N-dimethyltryptamine and harmala alkaloids in human plasma after oral dosing with Ayahuasca. J Anal Toxicol 1996;20:492-7. http:// dx.doi.org/10.1093/jat/20.6.492

3.Mckenna DJ, Towers GHN, Abbott FS. Monoamine oxidase inhibitors in South American hallucinogenic plants: Tryptamine and B-carboline constituents of ayahuasca. J Ethnopharmacol 1984;10:195-223.

4.Strassman RJ, Qualls CR. Dose response study of N,N-dimethyltryptamine in humans I: Neuroendocrine, autonomic, and cardiovascular effects. Arch Gen Psychiatr 2001;51:85-97. http://dx.doi.org/10.1001/archpsyc. 1994.03950020009001

5.Pires APS. Estudos de farmacocinética dos alcalóides da ayahuasca (Tese). São Paulo: USP, 2009, 154p.

6.Wagner H, Bladt S, Zgainsky E. Plant Drug Analysis. 2a edição. Berlin: Springer, 1984, 369p.

7.Simóes CM. Farmacognosia: da planta ao medicamento. 6a edição. Porto Alegre: UFSC, 2007, 1102p.

8.West MJ. New stereological method of counting neurons. Neurobiol Aging 1993; 14:275-85. http://dx.doi.org/10.1016/0197-4580(93)90112-O

9.Mandarim-de-Lacerda CA. Manual de quantificação Morfológica: Morfometria, Alometria e Estereologia. 2a edição. Rio de Janeiro: UFRJ, 1994, 102p. 10.Mandarim-de-Lacerda CA. Stereological tools in biomedical research. Anais Acad Bras Ciênc 2003;75:469-86. http://dx.doi.org/10.1590/S000137652003000400006

11.Pakkenberg B, Gundersen HJG. Solutions to old problems in the quantitation of the central nervous system. J Neura Sci 1995;129:65-7. http://dx.doi. org/10.1016/0022-510X(95)00067-C

12.Costa MCM, Figueiredo MC, Cazenave SOS. Ayahuasca: a toxicological approach of the ritualistic use. Rev Psiq Clin 2005;32:310-8. http://dx.doi. org/10.1590/S0101-60832005000600001

13. Cazenave SOS. Banisteriopsis caapi: ação alucinógena e uso ritual. Rev Psiq Clin 2000;27:1-6.

14.Blas-Valdivia V, Cano-Europa E, Hernández-García A, Ortiz-Butrón R. Hippocampus and amygdala neurotoxicity produced by systemic lidocaine in adult rats. Life Sci 2007;81:691-4. http://dx.doi.org/10.1016/j. lfs.2007.07.007

15. Santos RG. Ayahuasca: chá de uso religioso. Estudo microbiológico, observações comportamentais e estudo histomorfológico de cérebro em Murídeos (Rattus norvegicus da linhagem Wistar). (Monografia). Brasilia: Faculdade de Ciências da Saúde, 2004, 38f. 